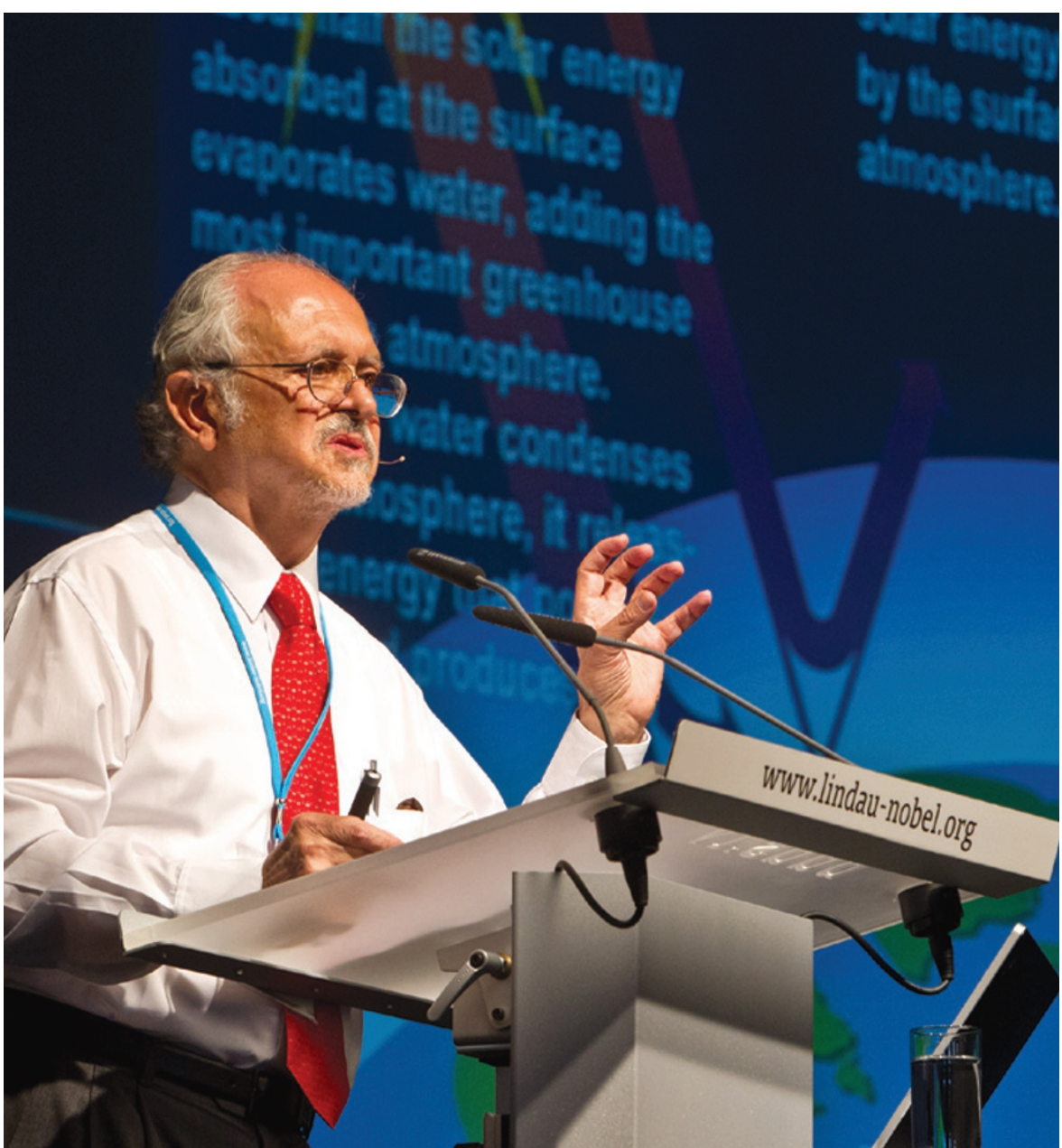

Q\&A MARIO MOLINA

\title{
Socially responsible science
}

The first Mexican-born scientist to become a Nobel laureate in chemistry,

Mario Molina shared the 1995 prize for his role in discovering the threat posed by chlorofluorocarbons (CFCs) to Earth's ozone layer. An optimist who passionately pursued science from a young age, Molina now focuses on finding practical solutions to environmental challenges.

At Lindau, you presented an optimistic outlook on our ability to tackle climate change, despite the scale of the challenge. What makes you so upbeat? My optimism comes from the fact that society is quite capable of fixing problems, as it did by acting on the problem of CFCs. On climate change, the message from energy experts is that solutions are possible at a reasonable cost. Some of the solutions, such as becoming more energy efficient, make sense irrespective of the climate change problem and would be inexpensive. Others, such as capturing and storing carbon dioxide, are expensive. But the problem can be addressed at a relatively modest cost - in the order of $1-2 \%$ of GDP, which is smaller than the cost of the potential damage caused by climate change.
Why, then, has the climate change problem not been solved?

It is difficult for society to undergo the enormous changes required to address the problem. Furthermore, there are many powerful interest groups that have launched a well-financed public-relations campaign involving the media to discredit climate change science.

This year at Lindau, physicist Ivar Giaever questioned the role of human activity in climate change. How would you advise budding scientists to respond to climate change sceptics?

As a scientist, you cannot be an expert on everything. I would advise young scientists to be well informed on important societal issues that involve a scientific

understanding of the problem, such as climate change. They should also be selective in their sources of information. With climate change, they have to be able to differentiate science from non-science opinion from fact.

You have said that certain facts in science, such as the existence of molecules, are incontrovertible, but that uncertainties remain in climate science. What would it take to make human-induced climate change an incontrovertible fact?

We shouldn't be looking for certainty in climate change as it would take too long to make climate change incontrovertible. Instead we have to think of climate change as an issue of risk management. Society is constantly evaluating risk. As an analogy, at some point measurements of stratospheric ozone depletion were considered to point to the risk of a hole developing in the ozone layer. Society has to act based on such risks.

The basic conclusion of the scientific community is that the climate is indeed changing as a result of human activities, with potentially very serious consequences for society. The scientific community is aware that the current understanding of the science of climate change is not perfect and that much remains to be learned, but enough is known to estimate the probabilities that certain events will take place if society continues with 'business as usual' emissions of greenhouse gases.

What is the focus of your current work? I hold a position at the University of California, San Diego, and also direct the Centro Mario Molina in Mexico City, where my focus is on science policy and communication. I collaborate with other experts, such as economists and engineers, to advise governments - including the Mexican government - on what makes sense in terms of sustainable development for greenhouse gas policy. For example, we are working on initiatives for Mexico such as providing incentives for solar energy to heat water, introducing fuel economy standards, and launching a pilot solar energy plant.

We are helping the government to consider regionally relevant policy options to tackle climate change, such as the use of photovoltaics in rural areas. We are

\section{"It's fine to be an advocate} as long as you remain honest with the science." rapid transit system in Bogota, Colombia. By dedicating one lane to buses, they provided a cheaper and complementary alternative to subways. We are learning from such 
$\frac{\infty}{0}$ initiatives and are especially interested in policies with co-benefits. Measures that address greenhouse gas emissions, for example, can also improve air quality. Our overarching goal is to help achieve sustainable development, and climate change is part of this. There are other issues though: reducing congestion, for example, is important for improving the quality of life in cities.

\section{When did you first become interested in science?}

I became interested in science as a child after reading biographies of famous scientists. Later, when I was about ten, I received a chemistry set as a present from my parents. I still remember how thrilled I was the first time I used a toy microscope to observe a drop of dirty water, teeming with life. Years later I took control of a bathroom that no one used at home and turned it into a laboratory, and I carried out more sophisticated chemistry experiments with the help of an aunt who was a chemist.

If you were starting out as a young climate researcher, where would you focus your efforts?

For chemists, many interesting questions remain. We still need a better understanding of how our planet functions and of atmospheric cycles, such as the nitrogen cycle. The science of extreme weather events is evolving rapidly and holds exciting possibilities for advancing understanding of climate change.

The work I undertook for my $\mathrm{PhD}$ was fundamental chemistry. We were able to measure concentrations of various compounds in the atmosphere and measure chemical reaction rates in the lab, and thereby confirm the composition of the atmosphere. Studying the urban atmosphere is much more complicated because it contains many more compounds and hence has many more reactions, not all of which can be well characterized in the lab. There is no shortage of interesting questions the challenge is to find a way of addressing something that has relevance to society or to advance fundamental science in some way.

\section{Would you advise young researchers to} be as outspoken on the urgency of the climate problem as you were on the risk of stratospheric ozone depletion?

Yes. I think they should speak out to make sure that society moves in the right direction. I hope that speaking out in public is no longer the problem it was when we made our ozone discoveries. It was not well regarded at the time for scientists to talk to the media. It's fine to be an advocate as long as you remain honest with the science. Science can tell you the consequences of a given action, but our values tell us what to

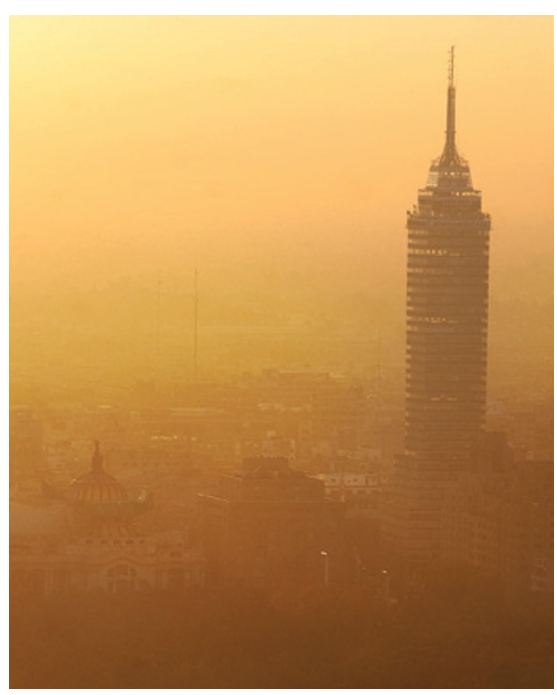

Mexico City: one of the cities likely to benefit from the work of the Mario Molina Centre on sustainable development.

do with that information. Science cannot tell us to be better people.

\section{t? If you could give pre-university students one piece of advice, what} would it be?

To be flexible. It's important to recognize that you might not actually like lab work or going to the mountains, so find out what you are good at and pursue it with passion. Also, I would advise them to be well informed and to start with a good foundation in science. You don't need to memorize the Periodic Table but you do need to understand how Mother Nature works!

Interview by Olive Heffernan, freelance science writer and former chief editor of Nature Climate Change in London.
\&3. Question
Minnie Mao, a postdoctoral researcher at the National Radio Astronomy Observatory in Socorro, New Mexico.

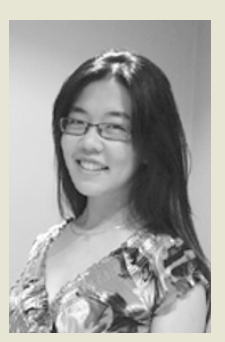
The advice is good and l'll definitely be keeping it in mind during my career. But I find it interesting that the advice is so science-centric. I wonder how his answer would have changed had I asked more explicitly about work-life balance.
$\rightarrow$ SCIENTIFICAMERICAN.COM You can visit Minnie's 30 Under 30 page: go.nature.com/BQ4cKA

\section{nature}

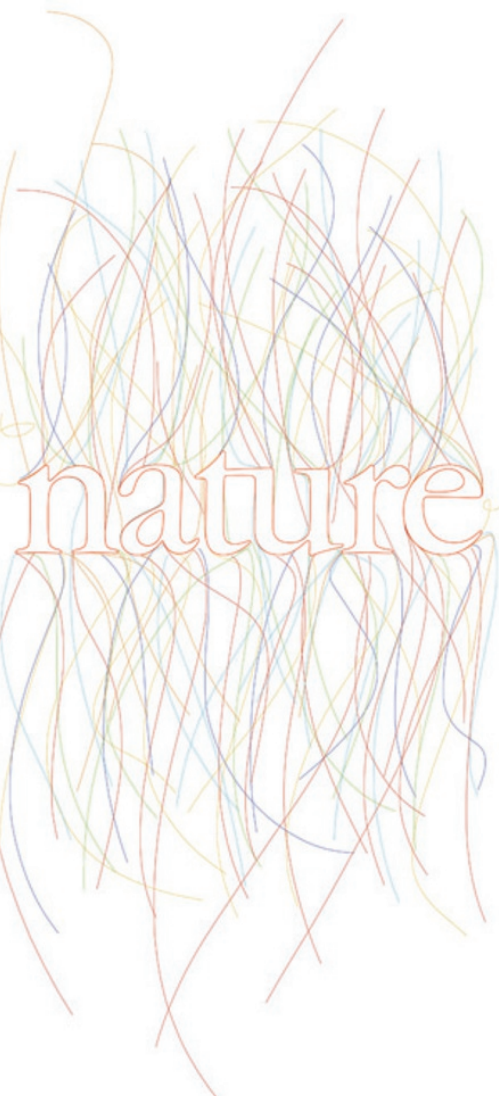

\section{A key thread in your scientific career}

\author{
Whether in print, online or \\ mobile, Nature is always at the \\ forefront of science and is your \\ forum to read, watch, listen and \\ engage with key research, news \\ and opinion.
}

\section{How will you access the next} landmark discovery?

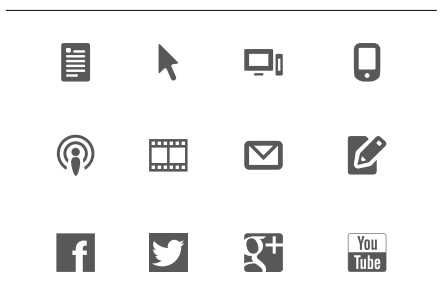

D NATURE.COM/NATURE 